\title{
Evaluation of antecedent rainfall effects in the analysis of the probability of transient failure in unsaturated slopes
}

\author{
Ana Paola do Nascimento Dantas, ${ }^{1, *}$, and André Luís Brasil Cavalcante ${ }^{1}$ \\ ${ }^{1}$ Department of Civil and Environmental Engineering, University of Brasilia, Zip Code 70910-900, Brazil
}

\begin{abstract}
The occurrence of extreme events of precipitation is commonly responsible for inducing surface mass movements in slopes. Landslides are due to the soil-atmosphere interactions. The main inducer of failure in unsaturated slopes is the infiltration, which triggers the reduction of suction, favoring the decrease of stability. Thus, this paper presents the implementation of analytical models to evaluate the probability of transient failure of slopes under unsaturated conditions for a local scale when subjected to antecedent precipitation. In this sense, the model proposed involves an analytical solution to Richards equation for unsaturated flow under transient conditions, capable of analyzing the soil behavior in the infiltration process. Therefore, these analytical models and the geotechnical parameters taken from the case study of a landslide that occurred in Nova Friburgo (Brazil) allowed the simulation of the infiltration process using the precipitation data corresponding to the day of the landslide, as well as four months previous to the collapse. The calculation routine is capable of generating the decreasing performance of the transient factor of safety and the increasing probability of transient failure through a probabilistic approach, allowing easy predicting failure and management of threat of landslides.
\end{abstract}

\section{Introduction}

High intensity or prolonged duration precipitation events are commonly responsible for inducing shallow landslides. In this context, according to the annual recurrence of landslides, the problem has gained much notoriety around the world and especially in Brazil, after experiencing the most massive natural disaster in Nova Friburgo (Rio de Janeiro state) in January 2011.

As reported by Orense et al. (2004) [1], the minimization of the damage caused by mass movements has been widely reported in two categories. One through invasive control techniques with slope stabilization methods, such as retaining walls, dewatering techniques, anchor piles, etc., and the soft approaches related to the slope monitoring and mass forecasting systems, using warning systems for the risk management and emergency action planning.

Thus, on account of the extent of potentially unstable natural slopes, the adoption of warning systems has been the most viable option due to financial and environmental constraints. In this way, to provide an accurate warning system, efforts have been made to understand the mechanisms and conditions that lead to these failures. Therefore, mathematical models have been developed, in addition to field monitoring systems and techniques for the assessment of spatial and temporal aspects of landslide hazards (Baum et al., 2010) [2].

In summary, the present paper intends to demonstrate analytical models' implementation to evaluate the probability of transient failures of slopes under unsaturated conditions for a local scale when subjected to extreme rainfall.

Furthermore, the model proposed involves an analytical solution to Richards equation for unsaturated flow and transient conditions capable of analyzing the soil behavior. The analytical models and the geotechnical parameters taken from the case study of a landslide that occurred in Nova Friburgo (Brazil) allowed the back analysis of the infiltration process using the precipitation data corresponding to the day of the landslide (January $11-12^{\text {th }}$ ), as well as four months previous to the collapse. These analytical models and geotechnical data were also used to provide the moisture content, the saturation degree, the total suction, and the unsaturated hydraulic conductivity of the Nova Friburgo slope.

The analytical solution was coupled to the slope stability analysis, specifically in a proposal of evaluating the transient factor of safety, based on the infinite slope method, which allowed the deterministic and a probabilistic approach of stability.

In this sense, this study presents an alternative to monitoring potential landslides in slope regions under extreme rainfall and could be a more straightforward prediction of possible collapse and the time when the slope will be in a critical situation. For more extreme conditions, this analysis can assist in planning the emergency response, allowing the slope to be vacated in a short time, thus avoiding the occurrence of disasters and fatalities.

\footnotetext{
* Corresponding author: anapaolans@gmail.com
} 


\section{The Study Region and Rainfall Characteristics}

The geotechnical and climatological references collected were related to the Floresta locality, belonging to the city of Nova Friburgo (Rio de Janeiro state). Nova Friburgo has a territorial area of $935.4 \mathrm{~km}^{2}$ and a population of 182,082 inhabitants. The city is located at Latitude $22^{\circ} 16^{\prime} 48^{\prime \prime} \mathrm{S}$ and Longitude $42^{\circ} 31^{\prime} 48 \mathrm{~W}$ (IBGE, 2010) [3].

Particularly, the geotechnical parameters of the Nova Friburgo slope (Fig. 1) were obtained from Guerra (2015) [4], and the author performed a set of laboratory tests during field visits in October 2014. During these field visits, undisturbed samples were taken in the layer corresponding to the observed rupture plane ( $3 \mathrm{~m} \mathrm{depth}$ ).

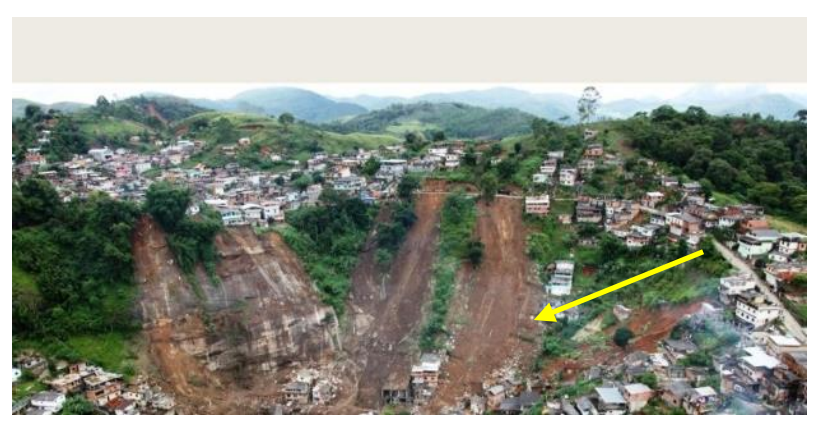

Fig. 1. Indication (yellow arrow) of the Nova Friburgo slope (Guerra, 2015) [4].

The geotechnical characterization results indicated percentages of clay, silt, and sand of $50 \%, 25 \%$, and $25 \%$, respectively, and corresponds to $\mathrm{CH}$, meaning a high plasticity clay, according to USCS (Unified Soil Classification System). Regarding the results of the other tests, the adopted geotechnical parameters are presented in Table 1.

Table 1. Adopted geotechnical parameters of Guerra (2015)[4]

\begin{tabular}{c|c|c}
\hline Symbol & Geotechnical Parameters & Input Values \\
\hline$\gamma_{\text {nat }}$ & Natural specific soil weight & $14.1 \mathrm{kN} / \mathrm{m}^{3}$ \\
$\theta_{\mathrm{i}}$ & Initial water content & 0.31 \\
$\theta_{\mathrm{s}}$ & Saturated water content & 0.60 \\
$\theta_{\mathrm{r}}$ & Residual water content & 0.12 \\
$\alpha$ & Slope angle & $31^{\circ}$ \\
$\mathrm{k}_{\mathrm{s}}$ & Saturated hydraulic & $10^{-6} \mathrm{~m} / \mathrm{s}$ \\
$\mathrm{c}^{\prime}$ & conductivity & $0.5 \mathrm{kPa}$ \\
$\phi^{\prime}$ & Effective cohesion & $31^{\circ}$ \\
\hline
\end{tabular}

According to Coelho Netto et al. (2011) [5], Nova Friburgo is the rainiest region of the state of Rio de Janeiro, with an average annual rainfall of around 2500 $\mathrm{mm}$. The periods of most significant precipitation occur, in general, between December and February.

Concerning the most critical landslide event that occurred in Nova Friburgo, the precipitation data refer to the day of the landslide (January $11-12^{\text {th }}$ ) and four months previous to the collapse. In this sense, it was used to verify the effects of the antecedent rainfall in the slope behavior.

The data used are available on the INMET (National Institute of Meteorology) website and correspond to the period from September $16^{\text {th }}, 2010$ to January $31^{\text {st }}, 2011$ (Fig. 2).

The rainfall data were used to verify the changes that occurred inside the soil, especially the changes in moisture content and total suction caused by rainwater infiltration that triggered the landslide on January $11-12^{\text {th }}$, 2011, as represented by the red dot in Fig. 2.

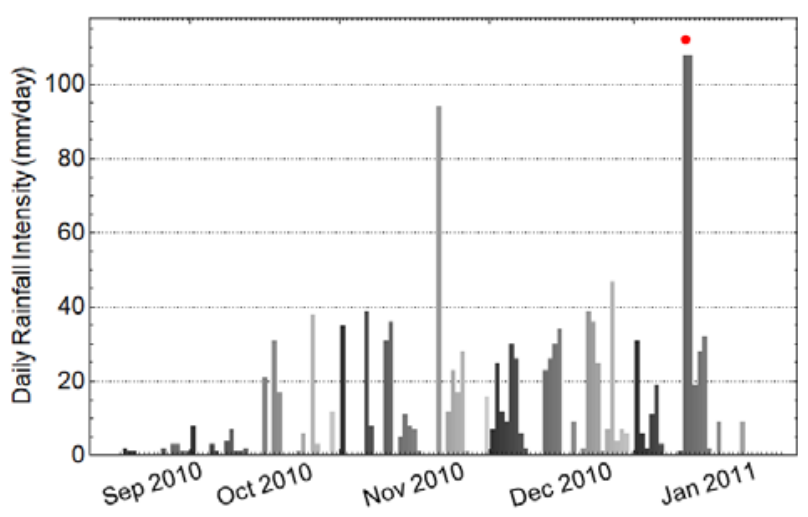

Fig. 2. Histogram of the daily rainfall intensity distribution $\left(\mathrm{mm} \cdot \mathrm{d}^{-1}\right)$ from September $16^{\text {th }}$ to January $31^{\text {st }}$, and the red dot represents the day of slope failure (118 ${ }^{\text {th }}$ day).

\section{Soil-Atmosphere Modeling with Transient Flow Analysis on Unsaturated Soil}

In this work, to perform the soil-atmosphere modeling, was analyzed the points of the Soil Water Retention Curve $(S W R C)$ of the Nova Friburgo slope soil, presented in Guerra (2015) [4], generated using the filter paper technique.

The tests were conducted according to Van Genuchten (1980) [6] and Chandler et al. (1992) [7] recommendations and the method used to obtain the points in the $S W R C$ was drying. Initially, saturated samples were taken to a residual moisture content $(60 \%$, $48 \%, 36 \%, 24 \%$, and $12 \%$ ), making successive measurements of tension as a function of $\theta$. The sample with $\theta_{i}$ of $31.3 \%$ was also tested as a point on the curve.

The points of the $S W R C$ and the physical indices [i.e., $\theta_{s}$ and $\theta_{r}$ ] (Tab. 1), both found experimentally, were implemented in constitutive models $\left[\psi(\theta)\right.$ and $\left.k_{z}(\theta)\right]$ proposed by Cavalcante \& Zornberg (2017) [8]. The constitutive models allowed the authors to propose an analytical solution to solve the Richards equation, as follows

$$
\begin{gathered}
\psi(\theta)=\frac{1}{\delta} \ln \left(\frac{\theta-\theta_{r}}{\theta_{s}-\theta_{r}}\right) \\
k_{z}(\theta)=k_{s}\left(\frac{\theta-\theta_{r}}{\theta_{s}-\theta_{r}}\right)
\end{gathered}
$$


Where $\delta=$ fitting hydraulic parameter $\left(\mathrm{M}^{-1} \mathrm{LT}^{2}\right) ; \theta=$ volumetric water content $\left(\mathrm{L}^{3} / \mathrm{L}^{3}\right) ; \theta_{r}=$ residual volumetric water content $\left(\mathrm{L}^{3} / \mathrm{L}^{3}\right) ; \theta_{s}=$ volumetric water content at saturation $\left(\mathrm{L}^{3} / \mathrm{L}^{3}\right)$. The fitting hydraulic parameter, $\delta$, consists of the initial angular coefficient of $S W R C$.

The calibration process of $\delta$ was performed by developing codes using the Wolfram Mathematica 11.0 Program. The FindFit command implemented the mathematical adjustment using the least square error criterion in the calibration process, resulting in a value of $\delta=0.0006 \mathrm{kPa}^{-1}$. With this value, it was possible to plot the $S W R C$ analytically and the unsaturated hydraulic conductivity function. Both functions are illustrated in Fig. 3(a)-(b).

(a)

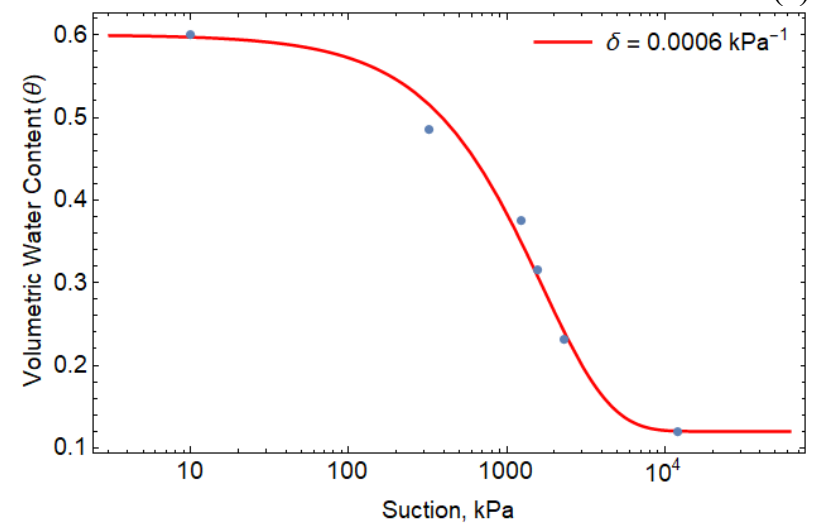

(b)

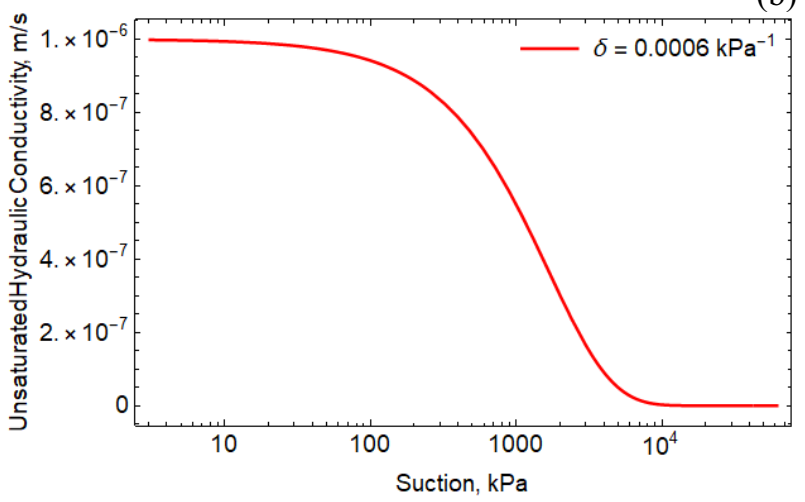

Fig. 3. Representation of analytically fitted curves in terms of (a) the SWRC and the representation by blue dots from the points obtained experimentally (b) unsaturated hydraulic conductivity function

It is worth mentioning, these constitutive models were proposed for soils with a unimodal behavior. However, the slope soil has tropical soil features, with fine grains forming lumps, which gives it a similar aspect to coarse fraction soil. This condition provides this soil with the distribution of micro-and macro-structures, named by bimodal soil, a common characteristic of tropical soils.

Analyzing Fig. 2, it is observed that although the soil of the Nova Friburgo slope presents characteristics compatible with tropical soil, the points obtained experimentally by the filter paper method have a unimodal desaturation, which allows the application of the constitutive models (Eqs. 1 and 2). Thus, the analytical model was appropriate to approach the experimental points.

Subsequently, was applied the analytical solution proposed by Cavalcante \& Zornberg (2017) [8] to solve the Richards equation. The proposal involves a modification of the flow equations by expressing the governing equation as the addition of advective and diffusive flow components and corresponds to the equation as follows

$$
\theta(z, t)=\theta_{i}+\left[\frac{v_{0}(t)}{k_{s}}\left(\theta_{s}-\theta_{r}\right)-\theta_{i}\right] C(z, t)
$$

Where

$$
\begin{aligned}
& C(z, t)=\frac{1}{2} \operatorname{erfc}\left(Z_{-1}\right)+\sqrt{\frac{\bar{a}_{s}^{2} t}{\pi \bar{D}_{z}}} \exp \left[-\frac{\left(z-\bar{a}_{s} t\right)^{2}}{4 \bar{D}_{z} t}\right] \\
& -\frac{1}{2}\left(-1+\frac{\bar{a}_{s} z}{\bar{D}_{z}}+\frac{\bar{a}_{s}^{2} t}{\bar{D}_{z}}\right) \exp \left(\frac{\bar{a}_{s} z}{\bar{D}_{z}}\right) \operatorname{erfc}\left(Z_{+1}\right)
\end{aligned}
$$

Where $\bar{D}_{z}=$ constant unsaturated water diffusivity in the $z$-direction; and $\bar{a}_{s}=$ constant unsaturated advective seepage; $v_{0}=$ water discharge velocity imposed on the upper boundary $\left(\mathrm{LT}^{-1}\right) ; \theta_{i}=$ initial moisture content $\left(\mathrm{L}^{3} / \mathrm{L}^{3}\right)$; and $\operatorname{erfc}\left(Z_{\mp_{1}}\right)=$ complementary error function.

These parameters can be defined as

$$
\begin{gathered}
\bar{D}_{z}=\frac{k_{s}}{\delta\left(\theta_{s}-\theta_{r}\right) \rho_{w} g} \\
\bar{a}_{s}=\frac{k_{s}}{\left(\theta_{s}-\theta_{r}\right)} \\
Z_{ \pm 1}=\frac{z \pm \bar{a}_{s} t}{2 \sqrt{\bar{D}_{z}} t}
\end{gathered}
$$

Where $z=$ thickness of the sliding mass (L); $\rho_{w}=$ fluid density $\left(\mathrm{ML}^{-3}\right)$; and $\mathrm{g}=$ acceleration of gravity $\left(\mathrm{LT}^{-2}\right)$;

Thus, the analytical solution for the unsaturated soil flow (Eq. 3 ) and the input of the adjustment parameter $(\delta)$ allowed to evaluate the changes in moisture content over four months of precipitation data (September 16 ${ }^{\text {th }}, 2010$ to January $31^{\text {st }}, 2011$ ) up to the landslide.

In summary, it was possible to construct graphically a slope moisture profile for the depth of $3.0 \mathrm{~m}$ (rupture plane) in terms of moisture content, saturation degree, total suction, and unsaturated hydraulic conductivity. The graphical results are shown in Fig. 4(a)-(d).

Analyzing Fig. 4(a-b) can be noted that occur an increase and a decreasing behavior on the curve according to humidity, which is expected after the imposition of the rainfall data (Fig. 2).

Initially, the moisture content is constant (Fig. 4a), due to the low precipitation intensity in the early days. In the next observation period (after the $10^{\text {th }}$ day), the low intensity of precipitation is maintained because of the dry season in the region. In this sense, a decrease in the moisture content value is observed until reaching the residual value. 
Around the $50^{\text {th }}$ day, the rainy season starts and can be noted an increase in the moisture content. Also, greater fluctuations in the moisture content are observed until reaching saturation, when prolonged, and high-intensity precipitation occurs at the end of the analysis period.

(a)

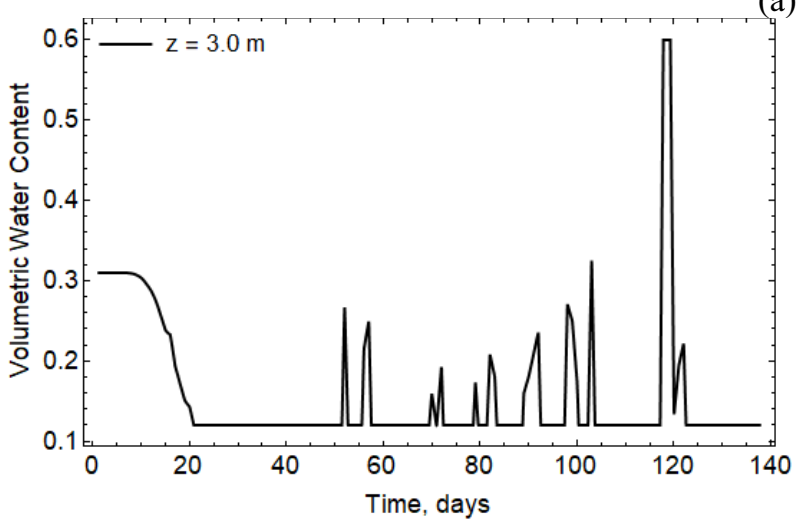

(b)

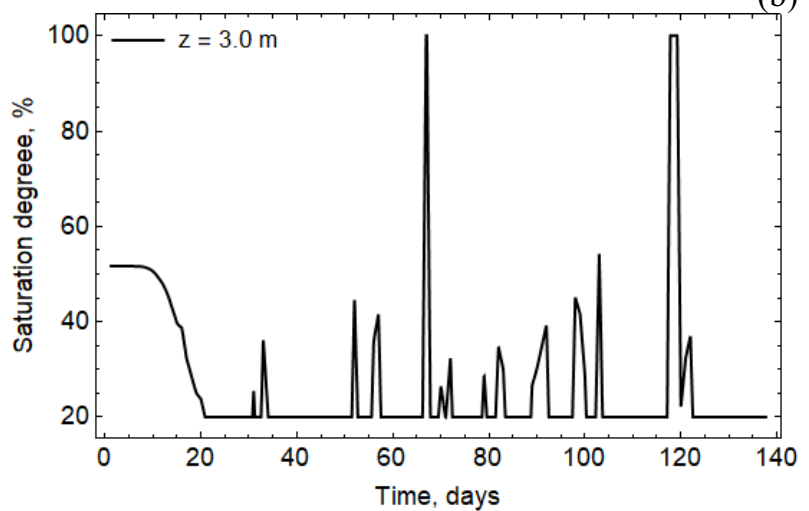

(c)

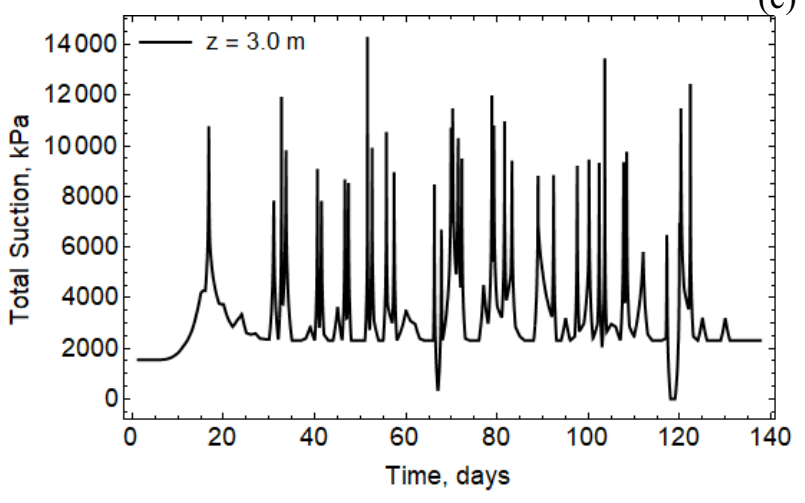

(d)

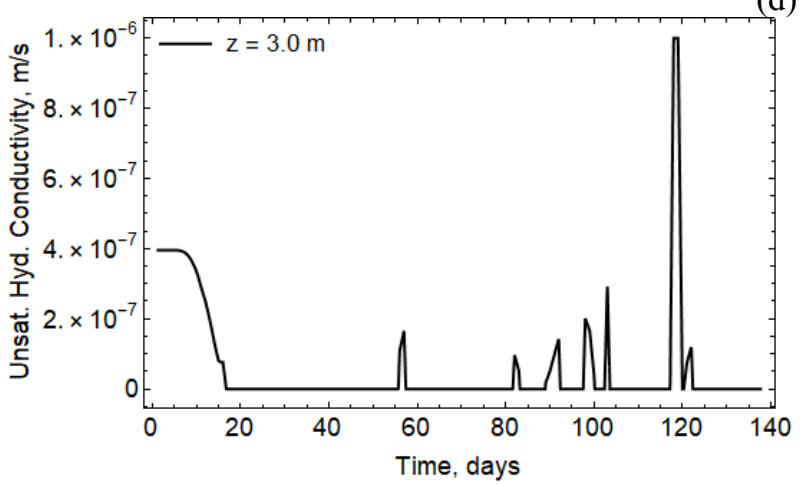

Fig. 4. Representation of a slope moisture profile in terms of (a) volumetric water content, (b) saturation degree, (c) total suction (d) and unsaturated hydraulic conductivity
The degree of saturation (Fig. 4b) has similar behavior to the volumetric water content and the same curve fluctuations due to the interdependence relations.

With regard to the total suction, this parameter has an inverse behavior of the water content. Fig. 4c shows greater fluctuations, and the suction results follow the daily rainfall data. This fluctuation aspect of the suction occurs due to the sensibility of this parameter related to the drying and wetting in the slope soil.

Related to the unsaturated hydraulic conductivity (Fig. 4d), it can be observed that occur a decrease in permeability in the early days. It happens due to the low precipitation intensity, which difficult water percolation. It reflects in the lower permeability of soil interstices to water flow. In contrast, in the rainy period, the conductivity increases and, consequently, the volumetric water content.

\section{Deterministic and Probabilistic Approach of the Slope Stability in Unsaturated Soils}

Two approaches were used in this research to evaluate the slope stability in unsaturated soils.

\subsection{Deterministic Approach}

One of the most widely used forms of slope performance evaluation in geotechnical engineering is the limit equilibrium method. This method embraces the classical analysis of infinite slope, generally implemented for stability analysis of natural slopes. Therefore, the method is appropriate when the horizontal dimensions of the surface are relatively more extensive than the vertical depth of the potential failure surface (Lade 2010 [9]; Egeli \& Firat Pulat 2012 [10]; and Shin et al. 2013 [11]).

In the transient analysis of the slope stability, Cavalcante \& Camapum de Carvalho (2017) [12] proposed an equation for evaluating the transient factor of safety, based on the infinite slope method. The model considers that the slide occurs in a translational way and parallel to the slope surface, with the extremity effects being neglected. The equation for the transient factor of safety $(F s(z, t))$ proposed by Cavalcante \& Camapum de Carvalho (2017) [12] is described by

$$
F S(z, t)=\frac{\tan \phi^{\prime}}{\tan \alpha}+\frac{c^{\prime}+\psi(z, t) \cdot \xi \cdot S_{r}(z, t) \tan \phi^{\prime}}{\gamma_{\text {nat }} \cdot z \cdot \cos \alpha \cdot \sin \alpha}
$$

where $\xi=$ positive constant dependent on porous soil constitution, history and magnitude of applied stresses and hysteresis during soil wetting and drying; $\psi(z, t)=$ total transient suction derived from the constitutive soil model proposed by Cavalcante \& Zornberg (2017) [8]; $S_{r}$ $(z, t)=$ degree of transient saturation expressed in terms of moisture content; $\gamma_{\text {nat }}=$ natural specific soil weight $\left(\mathrm{LM}^{-}\right.$ ${ }^{2} \mathrm{~T}^{-2}$ ); and $z=$ thickness of the sliding mass (L).

In this work, the determinist factor of safety evaluation was performed according to the Eq. (8), which also presents a fitting parameter $(\xi)$ related to the soil stress 
history, whose value is calibrated to adjust this equation about the results found analytically in $\psi(z, t)$ and $S_{r}(z, t)$.

Thus, for the exportation of better results for the stability analysis, was calculated the parameter $(\xi)$ by back-analysis of the slope taken as reference herein. The parameter was found using the documented conditions of the reference slope and the precipitation of $108 \mathrm{~mm}$, which triggered the slope failure that occurred between January $11-12^{\text {th }}$ of 2011 and an antecedent rainfall of about four previous months, as presented in Fig. 2. Accordingly, the adjustment value $(\xi)$ was 0.009 , and the graphical representation is illustrated in Fig. 5.

Fig. 5 shows the $F_{s}(z, t)$ oscillations according to precipitation data (Fig. 2). The curve tends to decline as there is an increase in precipitation intensity. This situation demonstrates the interdependence of stability with the infiltration process, which means that the $F s$ tend to a critical value when the suction decrease. It represents a reduction in normal contact stresses and consequently, in the soil resistance.

The failure occurs in approximately 118 days when the $F_{S}(z, t)=1,02$. It is important to note that the $F_{S}=1.02$ would not represent a failure in theoretical terms because FS $>1$. However, for real situations, this value is characterized as the imminence of failure and already indicates a critical situation as the real situation related in this research.

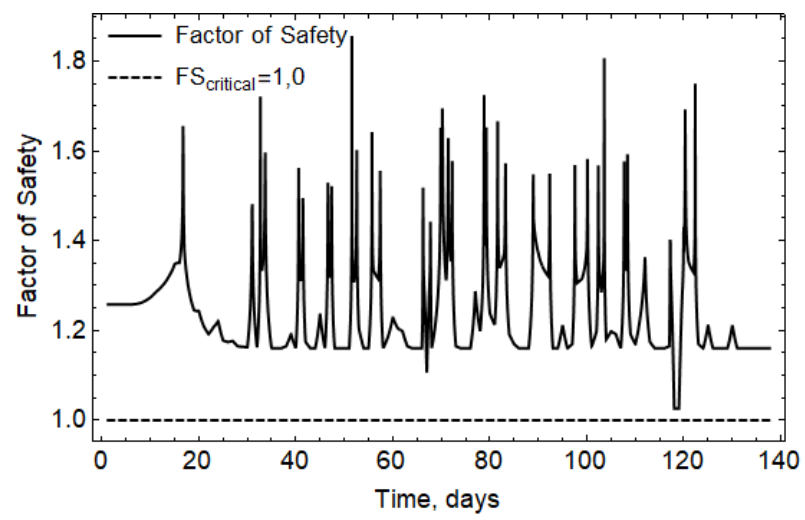

Fig. 5. Representation of the deterministic approach $(F s(z, t))$

\subsection{Probabilistic Approach}

The probabilistic evaluation is more efficient than the deterministic approach to consider the uncertainties and randomness in engineering problems (Ang and Tang 1975 [13], El-Ramly 2001 [14], Baecher and Christian 2003 [15]). Due to this variability, there is a distribution of acceptable values for each variable in relation to the average value, which refers to the coefficient of variation $(C V)$. The $C V$ is the relationship between the standard deviation and the mean of the variable.

Then, in this work, the consideration of this variability, expressed in terms of the $C V$ was performed for the physical parameters (i.e., $\gamma_{\text {nat }}$ and $\theta_{i}$ ), mechanical (i.e., $c^{\prime}$ and $\phi^{\prime}$ ), and hydraulic parameters (i.e., $k_{s}$ ); and in relation to the other parameters $\alpha$ and $\xi$, which were considered constant $\left(\alpha=31^{\circ}\right.$ and $\left.\xi=0.009\right)$, in the data input of Eq. 8 of the performance function $(F s)$.
To establish the $C V$ values of each input parameter, values listed by Baecher \& Christian (2003) [15] were collected with ranges suggested by several authors (Lumb 1974 [16], Lee et al. 1983 [17], Lacasse and Nadim 1996 [18]) and values also recommended by Duncan (2000) [19] and Gitirana Jr. (2005) [20].

All suggested typical values of soil property variability used in Eq. 8 with their appropriate sources, and the values adopted are presented in Table 2.

Table 2. Typical CV values and values adopted

\begin{tabular}{|c|c|c|c|}
\hline Symbol & $\begin{array}{l}\text { Typical } \\
\text { CV (\%) }\end{array}$ & Input Values & $\begin{array}{l}\text { Adopted } \\
\text { CV (\%) }\end{array}$ \\
\hline$\gamma_{\text {nat }}$ & $3-10$ & $\begin{array}{l}\text { Lumb (1974) [16] e } \\
\text { Duncan (2000) [19] }\end{array}$ & 3 \\
\hline$\theta$ & $6-63$ & Lee et al. (1983) [17] & 8 \\
\hline $\mathrm{ks}_{\mathrm{s}}$ & $68-90$ & Duncan (2000) [19] & 68 \\
\hline$c^{\prime}$ & $20-50$ & $\begin{array}{l}\text { Lee et al. (1983) [17] } \\
\text { and Gitirana Jr. (2005) } \\
\text { [20] }\end{array}$ & 50 \\
\hline$\phi ’$ & $2-13$ & $\begin{array}{c}\text { Lacasse and Nadim } \\
\text { (1996) [18]; Duncan } \\
\text { (2000) [19]; and Gitirana } \\
\text { Jr. (2005) [20] }\end{array}$ & 10 \\
\hline
\end{tabular}

Once the $C V$ values were established, the Point Estimation Method (PEM) was elected to apply the probabilistic approach. The Point Estimation Method was used because it requires only the mean and standard deviation of the data. Also, the method simplifies the determination of statistical moments since it is not necessary to calculate derivatives.

According to Baecher \& Christian (2003) [15], although the method is quite popular in practice, some researchers criticize the paper by Rosenblueth (1975) [21], idealizer of the method, for containing equations that are difficult to interpret and for the excessive approximation presented in their results. However, as the authors herein presented, the method includes a mathematical rigor in the theoretical foundation and that it is, appropriately, an application of the approximate Gaussian quadrature procedure in the determination of moments of a function.

Following PEM's theoretical foundation, the first and second moments of the $F_{S}(z, t)$ were determined by calculating the performance function estimates. According to the five random variables considered (Table 2 ), it was possible to generate 32 possible combinations of these variables, and consequently, 32 estimative points were determined for the $F_{S}(z, t)$.

The evaluation routine to calculate the failure probability of slope

According to the PEM application, the calculation routine consisted of finding the values of the mean and variance of $F s$ using the 32 estimation points. Then, the probability of failures could be determined by the area of the range bounded by Probability Density Function $(P D F)$, where the $F s$ values are less than unity. $P D F$ is the distribution of probability mass over sample space. Probability is then found by integrating the probability mass over a finite region of a sample space (Baecher \& Christian 2003) [15]. 
The Cumulative Density Function $(C D F)$ is the probability that the outcome of $F s$ is less than or equal to a particular value $(\mathrm{Fs}<1)$.

Firstly, the $P D F$ implementation (Fig. 6) consisted of determining the relative frequency of the $F_{S}$ distribution values to the slope when subjected to the correspondent rainfall $118^{\text {th }}$ day. This specific day represents the day of the documented failure on the Nova Friburgo slope.

Fig. 6 shows ranges from 0.2 to 2.0 , which means all the possible $F s$ values (32 estimative points) according to each input uncertainties and the relative frequency of $F S$. Concerning the distribution of $F s$ values, it could be noted that there is a high relative frequency when $F s$ values less than 1 are analyzed. This condition represents a warning situation due to the proximity to the critical values of $F S$.

Secondly, by implementing the $C D F$ (Fig. 7) was verified the probability of the $F s$ reaching values less than unity. Then, the $P_{f}$ found for the $118^{\text {th }}$ day when the $F_{S}$ is equal to 1 was $P_{f}=0.46$, which already indicates a high possibility of collapse.

The high $P_{f}$ value found is due to all conditions previously represented by the hydraulic parameters (Fig. 4). The high intensity of precipitation increased the value of moisture content and decreased suction, which consequently increased the probability of slope failure.

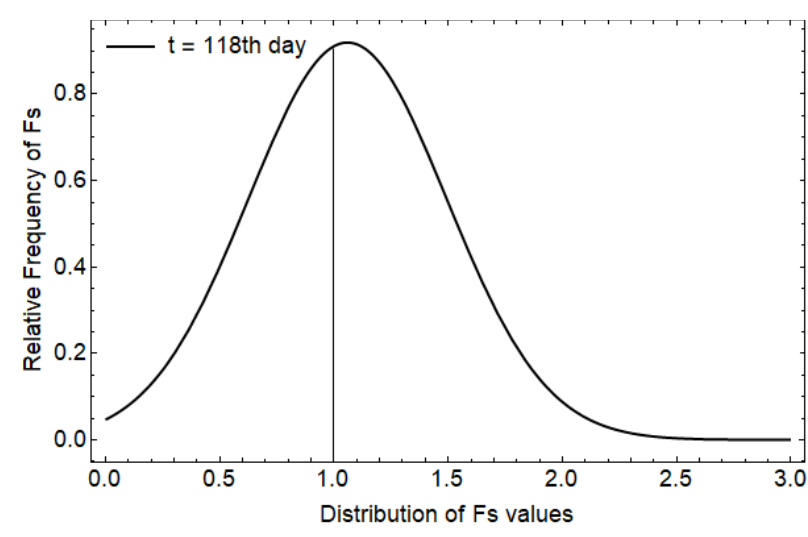

Fig. 6. Relative frequency of $F s$ for a depth of $\mathrm{z}=3 \mathrm{~m}$ and time at $\mathrm{t}=118^{\text {th }}$ day.

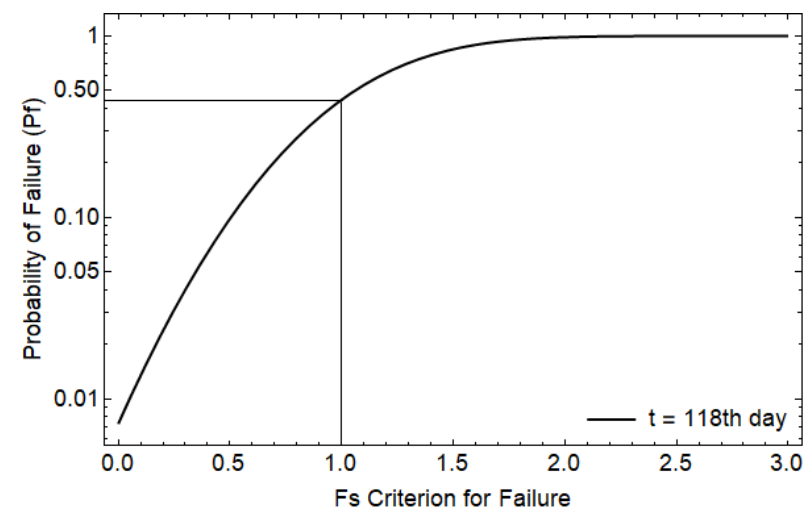

Fig. 7. Cumulative distribution function of $F s$ for a depth of $\mathrm{z}=$ $3 \mathrm{~m}$ and time-varying at $\mathrm{t}=118^{\text {th }}$ day.

One of the main purposes of this work is to calculate the probability of transient slope failure. Thus, to determine the slope behavior over time, the probability of transient failure $P_{f}(z, t)$, a function of the reliability index, was implemented. Both parameters $\beta(z, t)$ and $P_{f}(z, t)$ can be calculated as

$$
\begin{gathered}
\beta(z, t)=\frac{E(f(z, t))-1}{\sigma_{f}(z, t)} \\
P_{f}(z, t)=P\left(y<y_{\text {critical }}\right)=1-\frac{1}{2} \operatorname{erfc}\left(-\frac{\beta(z, t)}{\sqrt{2}}\right)
\end{gathered}
$$

Where $E(f)=$ mean of the performance function $f$; and $\sigma_{f}=$ standard deviation of the performance function $f$.

To determine the transient probability of failure, Eq. 10 was implemented, and the results are shown in Fig. 8.

However, to judge the acceptable behavior of the slope, quantitative limits of acceptance of the slip threat (i.e., probability of admissible failure) must be established. For this work, the probability of admissible failure was $P_{f, c r}=5 \times 10^{-2}$, and was determined as a recommendation by El-Ramly (2001) [14].

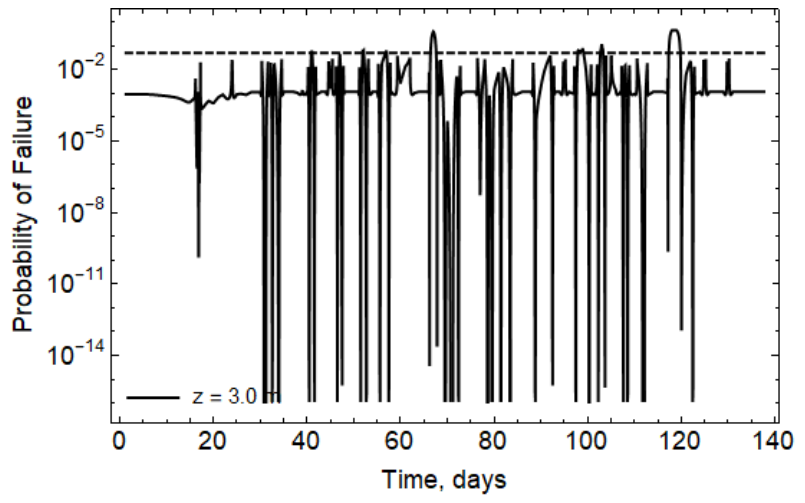

Fig. 8. Representation of the probabilistic approach $\left(\mathrm{P}_{\mathrm{f}}(\mathrm{z}, \mathrm{t})\right)$

According to Fig. 8, there are nine points at which the slope would exceed the critical limit. Comparing these nine points with the histogram in Fig. 2, it can be seen that the high intensity of precipitation does not always cause a failure susceptibility on the slope. With this, can be affirmed that an undesired performance of the slope is directly related not only to the intensity but also to the duration and recurrence of this rain (antecedent rainfall) data, which were used four months previous to the collapse.

Then, in the analysis of surface landslides generated by extreme rainfall, antecedent precipitation should be analyzed whenever possible.

\section{Conclusions}

In the present study, analytical models have been carried out to evaluate the probability of transient failure of unsaturated slopes under high rainfall rates and antecedent precipitation. The model involving an analytical solution to Richards equation was applied, especially to verify the changes in the geotechnical parameters with the application of the precipitation data to the day of the landslide (January $11-12^{\text {th }}$ ), as well as over four months previous to the collapse. 
This paper also compares the deterministic and probabilistic approaches of slope stability, which provided results regarding the stability performance over time analyzed under these two aspects.

Therefore, the following general conclusions can be drawn based on this work:

1. The $S W R C$ obtained analytically by constitutive models showed similar behavior to the points obtained experimentally by the filter paper method, which shows that the models are representative. These models proved to be efficient because they were calibrated for only one hydraulic adjustment parameter.

2. The analysis of four months of rain data allowed a complete analysis of the behavior of the slope in a period of low and high precipitation. It was possible to observe the fluctuations in the moisture content and degree of saturation with the infiltration process. The processes of saturation and desaturation of the soil were consistent with the periods of precipitation observed in Fig. 2.

3. In contrast to the analyzes observed in the moisture content and degree of saturation, the suction presented an opposite behavior, decreasing with the increase of the saturation. These changes in the suction values imply an increase in the value of the surface pore pressure of the soil and specific weight, characterizing variations in shear strength. These variations resulted in critical slope behavior observed in Figs. 5 and 8.

4. A comparison between the deterministic and probabilistic approaches of slope stability analyses was performed. As expected, the safety factor varied with precipitation rate changes and has a safety factor value close to the unity on the same day of the documented collapse, around the $118^{\text {th }}$ day. However, the same analysis about the occurrence of slope failure was performed applying the probabilistic approach and was obtained nine moments of possible landslide threats that exceeded the threshold judged as critical behavior, including that indicated by the deterministic approach. It is important to observe that the probabilistic approach is more reliable than the deterministic evaluation to demonstrate more than one critical situation.

5. The comparison between the two slope stability approaches showed the importance of a global analysis of rain data and not just the day of the documented failure. For this reason, the probabilistic analysis showed 8 points of attention, in addition to the $118^{\text {th }}$ day (documented failure). This kind of evaluation increases the slope's reliability.

6. Based on this research, a failure probability assessment could be used to monitor potential slope regions for landslides under extreme rainfall and can easily predict possible collapse and predict the time when the slope will be in a critical situation.

7. For more extreme conditions, this analysis can assist in planning the emergency response, allowing the slope to be vacated in a short time, thus avoiding the occurrence of disasters and fatalities.

\section{Acknowledgments}

This study was financed in part by the Coordination for the Improvement of Higher Education Personnel - Brazil (CAPES) - Finance Code 001. The authors also acknowledge the support of the National Council for Scientific and Technological Development (CNPq Grant 304721/2017-4, 435962/2018-3, 140570/2018-7 and 305484/2020-6), the Foundation for Research Support of the Federal District (FAPDF) (Projects 0193.002014/2017-68 and 0193.001563/2017), CEB Geração S.A. (AINOA Software - Monitoring System for Internal Pathologies in Earth and Rockfill Dams Based on Artificial Intelligence and Internet of Things: Case Study of the Paranoá-DF Dam), and the University of Brasília.

\section{References}

1. R. P. Orense, S. Shimoma, K. Maeda, I. Towhata. (2004). Instrumented model slope failure due to water seepage. J. Nat. Disaster Sci. 26 (9): 15-26, doi: 10.2328/jnds.26.15

2. R. L. Baum, J. W. Godt, W. Z. Savage. (2010). Estimating the timing and location of shallow rainfall-induced landslides using a model for transient, unsaturated infiltration. J. Geophys. Res. Earth Surf. doi:10.1029/2009JF001321

115(3):1-26,

3. IBGE (2011). Panorama da Cidade de Nova Friburgo (Rio de Janeiro state - Brazil). Available in: https://cidades.ibge.gov.br/brasil/rj/novafriburgo/panorama. Accessed in: 22 Feb. 2021

4. U. G. Guerra. (2015). Retroanálise de Rupturas de Taludes em Nova Friburgo - RJ. Dissertação de Mestrado. COPPE, UFRJ, Rio de Janeiro, RJ, 81 p.

5. A. L. Coelho Netto, A. M. Sato, A. S. Avelar, L. G. G. Vianna, I. S. Araújo, D. L. C. Ferreira, P. H. Lima, A. P. A. Silva, R. P. Silva. (2011). January 2011: the extreme landslide disaster in Brazil. Proceedings of the Second World Landslides Forum. Rome, Italy, 3: 377-384.

6. M. Th. Van Genuchten. (1980). A Closed-form Equation for Predicting the Hydraulic Conductivity of Unsaturated Soils. Soil Sci Soc Am J, v.44, pp. 892-898.

doi: 10.2136/sssaj1980.03615995004400050002x

7. R. J. Chandler, M. S. Crilly, G. Montgomery-Smith. (1992). A Low-Cost Method of Assessing Clay Desiccation for Low-rise Buildings. In: Proceedings of the Institute of Civil Engineering. V. 2, pp. 82-89.

8. A. L. B. Cavalcante \& J. G. Zornberg. (2017). Efficient approach to solving transient unsaturated flow problems. I: Analytical Solutions. ASCE. 17(7): 1-17, doi: 10.1061/(ASCE) GM.1943-5622.0000875

9. P. V. Lade. (2010). The mechanics of surficial failure in soil slopes. Eng. Geol. 114(1): 57-64, doi: 10.1016/j.enggeo.2010.04.003

10. I. Egeli \& H. Firat Pulat. (2012). Mechanism and modelling of shallow soil slope stability during high 
intensity and short duration rainfall. Sci. Iran. 18(6): 1179-1187, doi:10.1016/j.scient.2011.09.010

11. H. Shin, Y. Kim, D. Park. (2013). Development of rainfall hazard envelope for unsaturated infinite slope. J. Civ. Eng., 17(2): 351-356, doi: 10.1007/s12205-013-1626-9

12. A. L. B. Cavalcante \& J. Camapum de Carvalho, (2017). Probabilidade de ruptura transiente de taludes não saturados em bordas de reservatórios. Erosão em Bordas de Reservatório. M. M. Sales, J. Camapum de Carvalho, M.M.A. Mascarenha, M.P. da Luz, N. M. de Souza \& R. R. Angelim (eds.), Goiânia, GO, pp 469-487.

13. A. H-S. Ang \& W.H. Tang. (1975). Probability Concepts in Engineering Planning and Design. John Wiley and Sons, New York, 562 p.

14. H. El-Ramly. (2001). Probabilistic Analyses of Landslide Hazards and Risks: Bridging Theory and Practice. Ph.D. Thesis, University of Alberta, Edmonton, Canada, $391 \mathrm{p}$.

15. G.B. Baecher \& J. T Christian. (2003). Reliability and Statistics in Geotechnical Engineering. John Wiley \& Sons Ltd, England, 605 p.

16. P. Lumb. (1974). Application of statistics in soil mechanics. Soil Mechanics: New Horizons. Lee, I. K. (eds.), London, Newnes-Butterworth: 44-112, 221239.

17. I. K. Lee, W. White, O. G. Ingles. (1983). Geotechnical Engineering. Boston, Pitman.

18. S. Lacasse, F. Nadim. (1996). Uncertainties in characterizing soil properties. Norwegian Geotechnical Institute, Olso, Norway, 201:49-75.

19. J. M. Duncan. (2000). Factors of safety and reliability in geotechnical engineering. J. Geotech. Geoenviron. Eng., ASCE, 126(4):307-316, doi: 10.1061/(ASCE)1090-0241(2000)126:4(307)

20. G. F. N. Gitirana Jr. (2005). Weather-Related GeoHazard Assessment Model for Railway Embankment Stability. Ph.D. Thesis, University of Saskatchewan, Saskatoon, Canada, 439 p.

21. E. Rosenblueth. (1975). Point estimates for probability moments. Proc. Natl. Acad. Sci. U.S, 72(10): 3812-3814, doi: 10.1073/pnas.72.10.3812 